http://www.jfas.info

\title{
THEORETICAL MODELING OF A NEW STRUCTURE OF III-V TANDEM SOLAR CELLS BY USING PARABOLIC TROUGH CONCENTRATOR
}

\author{
R. Ganouni*, M. Talbi, H. Ezzaouia \\ Center of Research and Technologies of Energy of Borj-Cedria, Tunis, Tunisia
}

Published online: 15 February 2017

\begin{abstract}
In this study, potential efficiency of GaInP/GaAs mechanically stacked two-junction solar cell is theoretically investigated by optimizing the thickness of GaAs and GaInPandusing a new optical model to separate the junction between the two solar cell in order to solve problems of tunnel junction and difficulties of fabrication. The principal of this new model is inspired from that of parabolic trough concentrator.Results show that the optimum conversion efficiency is $43 \%$ under AM1.5 spectral illuminations. The obtained results from computation and Matlab simulation of three fundamental parameters which are Reflectance $\mathbf{R}$, external quantum efficiency $\mathbf{Q E}$ and current density $\mathbf{J}$, would be helpful in designing and fabricating high efficiency GaInP/GaAs mechanically stacked solar cell in experiment.
\end{abstract}

Keywords: GaInP/GaAs; parabolic trough concentrator; optical model; AM1, 5 illumination.

\section{INTRODUCTION}

Solar photovoltaic conversion methods can be broadly divided into crystalline wafer-based and alternative approaches. Recent world records have been set for wafer-based cells with one to three distinct photovoltaic absorber materials: $28.3 \%$ for GaAs single junctions, $36.9 \%$ for GaInP/GaAs tandem cells, and 43.5\% triple-junction of GaInP/GaAs/GaInAs under 418 sun concentrations [1]. Alternative photovoltaic technologies generally offer a substantial discount of $15-20 \%$ in cost relative to crystalline wafer-based cells, at the expense of lower maximum efficiencies [2-3].

Author Correspondence, e-mail: rached.ganouni@yahoo.fr doi: http://dx.doi.org/10.4314/jfas.v9i1s.729 
Multi-junction (cascade or tandem) solar cells exploit so named spectrum separation principle [4]. It is well known that single-junction solar cells can convert to electric power solar radiation with photon energy equal and above the semiconductor material band-gap. However, if the photon energy sufficiently exceeds the band-gap, excessive energy is lost to the lattice for heating instead of charge carrier generation. To achieve more conversion efficiency rate, several junctions of semiconductor materials with different band-gaps are stacked on top of one another decreasing the band-gap value from the top junction to the bottom one. This makes it possible to split solar energy spectrum into several sub-bands and to treat separately each sub-band with an appropriate semiconductor material. Each upper junction absorbs photons with energy higher than band-gap value but within only relatively narrow energy sub-band and allows all photons with lower energy to pass through it to the lower junction which can absorb photons with energy from next sub-band. The total spectral response and conversion efficiency of a multi-junction solar cell can be obtained as a sum of those characteristics of all individual junctions (subcells). There is no formal limitation to the number of subcells, but in practice increasing the number of junctions over four or five has no significant effect. The most used multi-junction solar cells consist of three junctions however, investigations towards involving more junctions to the solar cell design are in the progress [5].For instance the most important keys to highly efficient MJ solar cells are the abilities to: First, match current of all junctions at the optimal working condition (By using tunnel junction). Second match the lattice constant of all epitaxial layers to the substrate to achieve high crystalline quality [6].

In this paper we will introduce a new provision tandem solar cell (based on parabolic trough concentrator) by using a model that will describe an innovation in the field of photovoltaic and avoiding the problems already announced. This model is based on a rigorous theoretical calculation using Matlab code (including optical and electrical modules). This article, focus on the design of a two junction GaInP/GaAs solar cell, under the standard AM1.5 solar spectrum, including the design of separation of cells and elimination of tunnel junction. Finally we determined the reflectance, current density and efficiency of this new model. 


\section{Theoretical approach}

In this paper we propose a new model of GaInP/GaAs tandem solar cell based on parabolic trough concentrator. This model is illustrated in Fig.1.

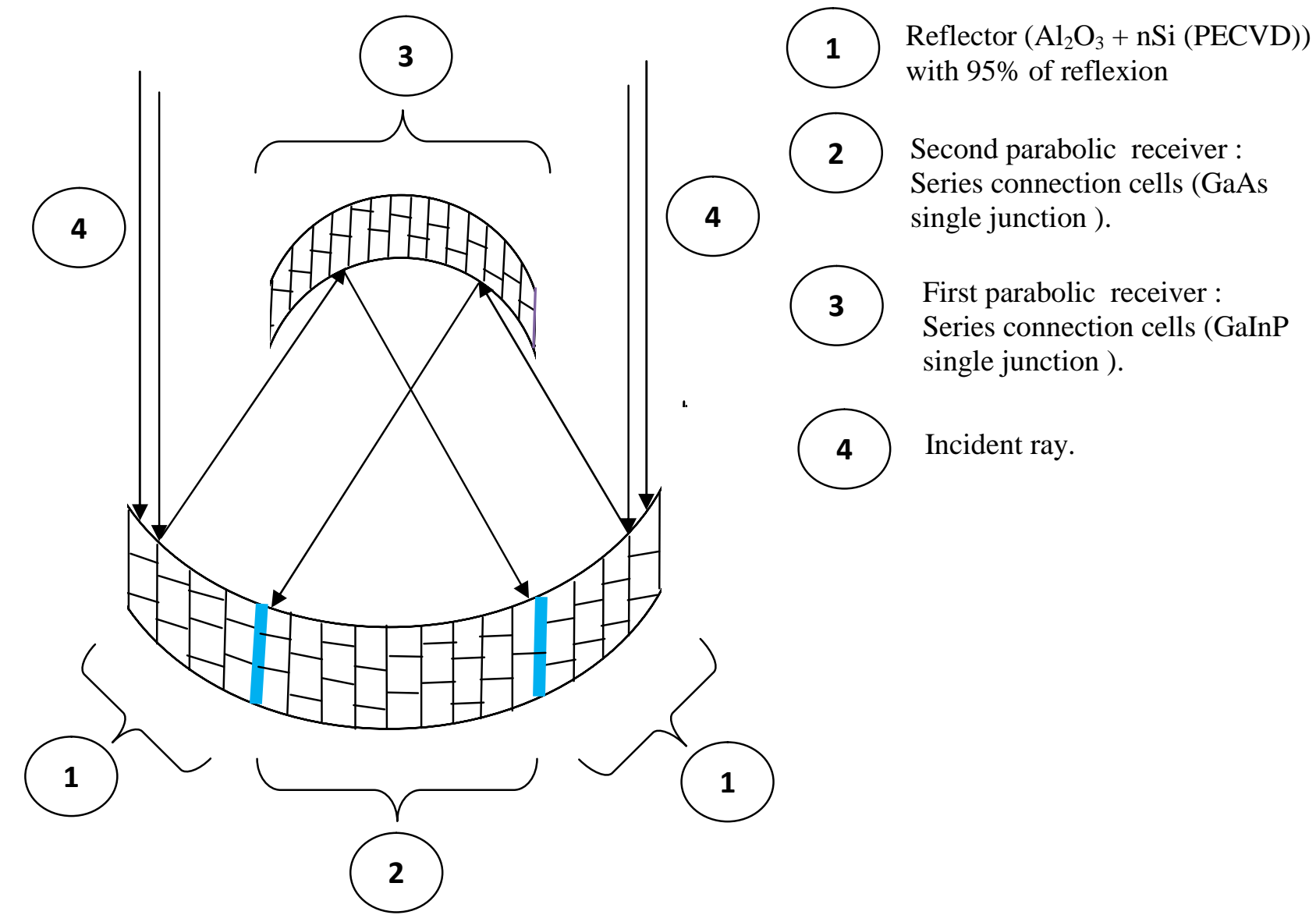

Fig.1. New model of tandem solar cells with parabolic trough concentrator(In French: concentrateur cylindro-parabolique).

As shown in Fig1, this model is constitutes of two parabolic systems. The first parabolic system includes a single region 2 located between two regions 1 having the same surface and each of them contains a reflector with $95 \%$ of reflexion (composed by $\mathrm{Al}_{2} \mathrm{O}_{3}+n \mathrm{ni}$ (PECVD)). The region 2 contains a GaAs single junction solar cells connected in series. Each of these solar cells is modeled in Fig.2.The second parabolic system contains a GaInP single junction solar cells connected in series, each of these solar cells is modeled in Fig.2.

Each of GaInP or GaAs cell is composed by absorbent layer $\mathrm{TiO}_{2}$, p-n junction and reflective layer $\mathrm{Al}_{2} \mathrm{O}_{3}$ (Fig.2 (a) GaAs single junction solar cells and (b) GaInP single junction solar cells). 


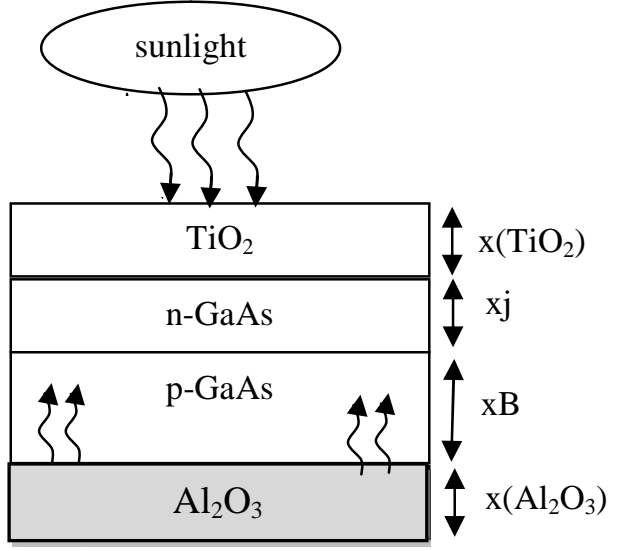

(a) GaAs single junction cell.

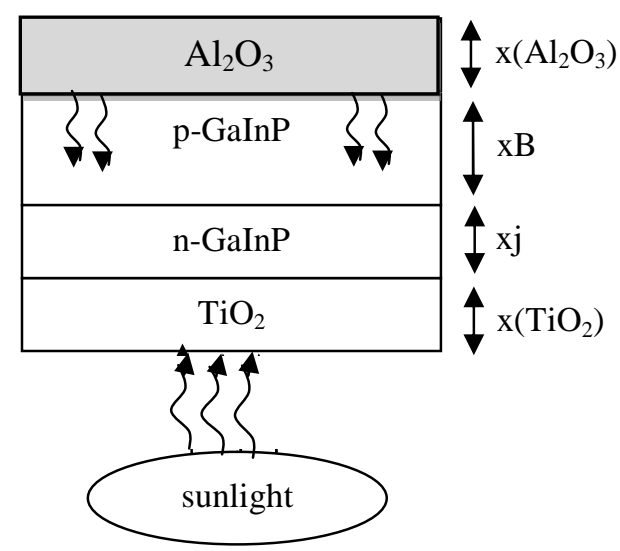

(b) GaInP single junction cell.

Fig.2. Composition of GaInP and GaAs solar cells

The spectrum of sunlight striking the front of the cell includes ultraviolet, visible and infrared light.Sunlight is reflected by reflector in region 1 (Fig.1) to the solar cell with high band gap (GaInP), the absorption coefficient for short-wavelength light is quite large, and most of blue light is absorbed very close to the front of GaInP cell. Light with energy close to, but above, the GaInP band edge is weakly reflected by the back surface of GaInP (contains a reflector $\mathrm{Al}_{2} \mathrm{O}_{3}$ ) throughout the cell and a large part reaches the GaAs cell. Light is reflected by the back surface of GaAs and we win the most of energy. The study of our structure is based on the calculation of three fundamental terms.Reflectance $\mathbf{R}$, external quantum efficiency $\mathbf{Q E a n d}$ current density $\mathbf{J}$.

The optical modeling proposed in this paper is based on the transfer matrix formalism. It allows calculation of the incident optical spectrum on each subcell from the solar cell spectrum. Each layer of the multi-junction is described by a transfer matrix Mwhich is defined by

$\mathrm{M}=\left(\begin{array}{ll}m_{11} & m_{12} \\ m_{21} & m_{22}\end{array}\right)=\left(\begin{array}{cc}\cos \left(\delta_{j}\right) & \frac{i \sin \left(\delta_{j}\right)}{N_{j}} \\ i N_{j} \sin \left(\delta_{j}\right) & \cos \left(\delta_{j}\right)\end{array}\right)(1)$

$\delta_{j}=\frac{2 \pi N_{j}}{\lambda} \mathrm{d}_{\mathrm{j}} ; \mathrm{N}_{\mathrm{j}}=\mathrm{n}_{\mathrm{j}}(\boldsymbol{\lambda})+\mathrm{i} \mathrm{k}_{\mathrm{j}}(\boldsymbol{\lambda})$

where $\mathbf{n}_{\mathbf{j}}(\boldsymbol{\lambda}), \mathbf{k}_{\mathbf{j}}(\boldsymbol{\lambda})$ and $\mathbf{d}_{\mathbf{j}}$ are the refraction, extinction index and the thickness of the layer respectively. $\lambda$ is the wavelength. The reflectance coefficient $R^{[5,6]}$ of the layer is then given by 
$\mathrm{R}=|r|^{2}=\left|\frac{n_{0} m_{11}+n_{0} n_{s} m_{12}-m_{21}+n_{s} m_{22}}{n_{0} m_{11}+n_{0} n_{s} m_{12}+m_{21}+n_{s} m_{22}}\right|^{2}$

Where $\mathbf{n}_{\mathbf{0}}$ is the superstrate refractive index and $\mathbf{n}_{\mathbf{s}}$ is the substrate refractive index. The $\boldsymbol{n}_{j, \boldsymbol{n}}$ coefficients refer to the matrix transfer elements. Thus, it is possible to search the appropriate thickness of layer to calculate QE and J.

Multi-junction cells behave like homojunction cells in series, and their open circuit voltage is the sum of the voltages of the subcells, while their short circuit is that of the subcell with the smallest current. Hence, the performance of a multi-junction cell can be obtained from the performance of each subcell evaluated independently. For each subcell, the load current density $\mathrm{J}$ is represented by the superposition of two diode currents and the photo-generated current,

$\mathrm{J}=I_{p h}-J_{01}\left(e^{q V / k T}-1\right)-J_{02}\left(e^{q V / 2 k T}-1\right)(3)$

where $\boldsymbol{J}_{\boldsymbol{p} \boldsymbol{h}}$ is the photocurrent density, $\mathbf{J}_{\mathbf{0 1}}$ is the ideal dark saturation current component, and $\mathbf{J}_{\mathbf{0 2}}$ is the space charge non-ideal dark saturation current component.

This model includes optical and electrical modules, with the optical modules allowing the research of the suitable thickness for each layer $\left(\boldsymbol{x}_{\boldsymbol{j}}, \boldsymbol{x}_{\boldsymbol{B}}, \boldsymbol{x}\left(\mathrm{TiO}_{2}\right)\right.$ and $\left.\boldsymbol{x}\left(\mathrm{Al}_{2} \mathrm{O}_{3}\right)\right)$ of $\mathrm{GaInP}$ and GaAs. Then, the electrical model calculates the photocurrents in the space charge region, the emitter and the base for each junction.

\section{Solar cell structure and parameters}

The wavelength-dependent reflectance coefficient of GaInP and GaAs is based on the research of fitting curves of extinction $\mathbf{n}_{\mathbf{j}}(\boldsymbol{\lambda})$ and refractive $\mathbf{k}_{\mathbf{j}}(\boldsymbol{\lambda})$ index.

The fit for this curves ${ }^{[6,7,8]}$ is given by :

$$
* \mathrm{n}(\boldsymbol{\lambda})[\mathrm{GaInP}]=3.26+\frac{8916.49}{4(\boldsymbol{\lambda}-408)^{2}}+21609 ; * \mathrm{k}(\boldsymbol{\lambda})[\mathrm{GaInP}]=-0.0169+\frac{34520}{4(\boldsymbol{\lambda}-334.2)^{2}}+15672
$$




$$
\begin{gathered}
* \mathrm{n}(\boldsymbol{\lambda})[\mathrm{GaAs}]=\frac{3.76}{1+1716.28 e^{-(0.034 \lambda)}} * * \mathrm{k}(\boldsymbol{\lambda})[\mathrm{GaAs}]=\frac{3.39}{1+e^{(\lambda-474.45)} / 84.75} \\
* \mathrm{n}(\boldsymbol{\lambda})\left[\mathrm{TiO}_{2}\right]=2.59+1.71 e^{\left\{1-\left(\frac{(\lambda-325.98)}{38.99}-e^{\frac{-(\lambda-325.98)}{38.99}}\right)\right\}} \\
* \mathrm{k}(\boldsymbol{\lambda})\left[\mathrm{TiO}_{2}\right]=1.167-1.162\left(\operatorname{coth}(\boldsymbol{\lambda}-336.26)-\frac{1}{\lambda-336.26}\right) \\
* \mathrm{n}(\boldsymbol{\lambda})\left[\mathrm{Al}_{2} \mathrm{O}_{3}\right]^{[9]}=2.29623+\frac{0.17963}{1+e^{\frac{(\lambda-53.1490)}{35.08544}}} \\
* \mathrm{k}(\boldsymbol{\lambda})\left[\mathrm{Al}_{2} \mathrm{O}_{3}\right]=0
\end{gathered}
$$

The incident photon fluxF for AM1.5 spectrum is taken by a fitting curve ${ }^{[10]}$.

$\mathrm{F}=\frac{\operatorname{Ecl}(\lambda)}{h c / \lambda}(4)$

$\operatorname{Ecl}(\lambda)=0.06977+7.0625\left[1-e^{\frac{-(\lambda-0.26053)}{0.15994}}\right]^{2.28411} e^{\frac{-(\lambda-0.26053)}{0.2285}}(5)$

With 300nm $<\lambda<1400 \mathrm{~nm}$.

Where $\operatorname{Ecl}(\lambda)\left(\mathrm{KW} / \mathrm{m}^{2} \mu \mathrm{m}\right)$ the illumination, h Plancks constant, c velocity of light.

The integrated ASTM Sub-commitee G3.09 AM1.5 solar spectral irradiance has been made to conform to the value of the solar constant accepted by the space community, which is 694 $\mathrm{W} / \mathrm{m}^{2}$.

The different variables of GaAs and GaInP are defined in Table.1 and Table.2.

Table.1.Values for the parametersof GaAs ${ }^{[11]}$ and $\mathrm{GaInP}^{[12]}$ used in the model calculation.

\begin{tabular}{lcc}
\hline ParametersGaAs & & \\
\hline Band gap Eg(ev) & 1.42 & 1.86 \\
The electron surface recombinationvelocity $S_{\mathrm{n}}(\mathrm{cm} / \mathrm{s})$ & $10^{2}$ & $1.7 \mathbf{1 0}^{6}$ \\
The hole surface recombination velocity $\mathrm{S}_{\mathrm{p}}(\mathrm{cm} / \mathrm{s})$ & $10^{6}$ & $10^{4}$ \\
Electron diffusion length $\mathrm{L}_{\mathrm{n}}(\mu \mathrm{m})$ & 25 & 3 \\
Hole diffusion length $\mathrm{L}_{\mathrm{p}}(\mu \mathrm{m})$ & 0.1 & 0.5 \\
Electron diffusion coefficient $\mathrm{D}_{\mathrm{n}}\left(\mathrm{cm}^{2} / \mathrm{s}\right)$ & 75 & 100 \\
Hole diffusion coefficient $\mathrm{D}_{\mathrm{p}}\left(\mathrm{cm}^{2} / \mathrm{s}\right)$ & 1 & 5 \\
\hline
\end{tabular}


Table.2. Values for the parameters ${ }^{[13]}$ of GaAsand GaInP used in the model.

\begin{tabular}{ccccc}
\hline ParametersGaAs & GaInP & & \\
\hline Concentration of acceptors $\mathrm{N}_{\mathrm{A}}\left(\mathrm{cm}^{-3}\right)$ & $\mathbf{1 0}^{18}$ & $\mathbf{1 0}^{18}$ & \\
Concentration of donors $\mathrm{N}_{\mathrm{D}}\left(\mathrm{cm}^{-3}\right)$ & $\mathbf{1 0}^{17}$ & $\mathbf{1 0}^{17}$ & \\
Intrinsic carrier concentration $\left(\mathrm{cm}^{-3}\right)$ & $2.1 \mathbf{1 0}^{6}$ & $\mathbf{1 . 9 ~ 1 0 ~}^{2}$ & \\
Permittivity & & 12.9 & & 11.8 \\
\hline
\end{tabular}

The absorption coefficient of GaInP ${ }^{[12]}$ can be fitted by

$\alpha_{\mathrm{GaInP}}=5.5 \sqrt{E-E_{g}}+1.5 \sqrt{E-E_{g}-1}(6)$

The absorption coefficient of GaAs ${ }^{[15]}$ can be fitted by

$\alpha_{\mathrm{GaAs}}=1.93 \sqrt{E-E_{g}}(7)$

Where $\mathrm{E}$ is the photon energy and $\mathrm{E}_{\mathrm{g}}$ is the fundamental band gap, both in $\mathrm{eV}$, and $\alpha$ in $1 / \mu \mathrm{m}$.

\section{Simulation and results}

In this section we have variedthe thickness of each layer in order to have from Matlab simulation, a suitable reflectance curve for each cell and this by referring to the ideal theoretical curve.In Fig.3 ((a) and (b)), are illustrated the reflectance curves obtained from Matlab simulation and from the theoretical formula given asfollow [16]:

$E_{g}(e V)=\frac{1.24}{\lambda_{g}(\mu m)}(8)$

Where $E_{g}(\mathrm{eV})$ and $\lambda_{g}(\mu \mathrm{m})$ are band gap energy and wavelength respectively. This formula explains the variation of $E_{g}(\mathrm{eV})$ vs $\lambda_{g}(\mu \mathrm{m})$ (Red curve in Fig.3: (a) and (b)).

For GaAs, $E_{g}(e V)=1.42$, this mean that $\lambda_{g}(\mu m)=0.88$. This result explain that GaAs absorb for $\lambda<880 \mathrm{~nm}$ (Reflectance $=0$ ) and reflect all light for $\lambda>880 \mathrm{~nm}(\mathrm{R} \cong 1)$.For GaInP, $E_{g}(\mathrm{eV})=1.86$, this mean that $\lambda_{g}(\mu \mathrm{m})=0.66$. This result explain that GaAs absorb for $\lambda<660 \mathrm{~nm}($ Reflectance $=0)$ and reflect all light for $\lambda>660 \mathrm{~nm}(\mathrm{R} \cong 1)$. 


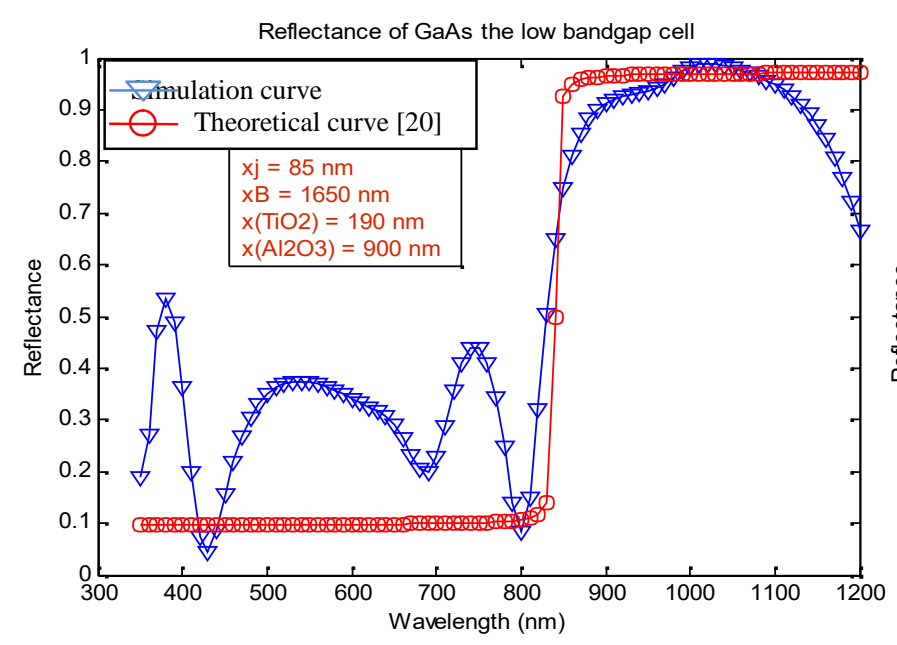

(a)

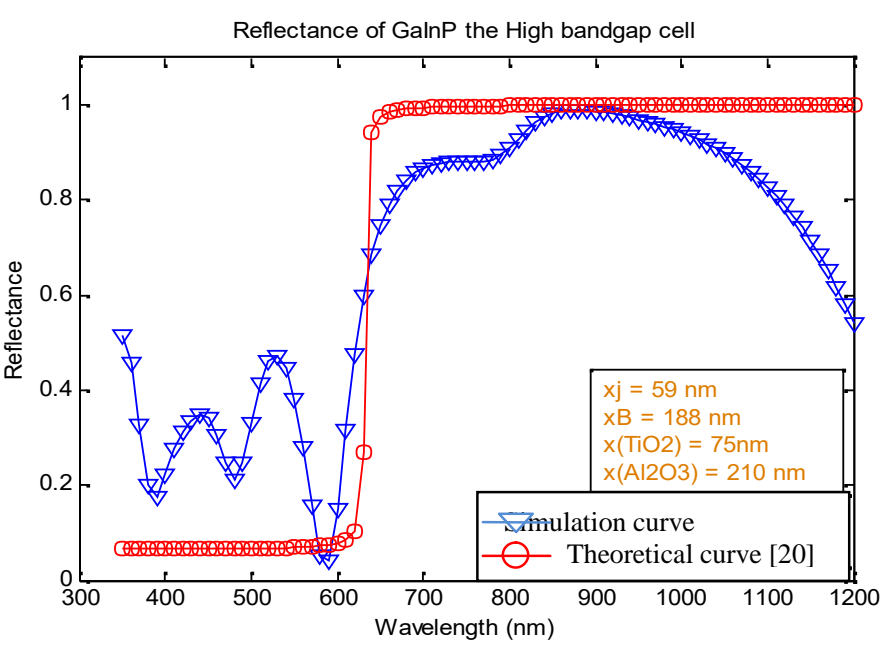

(b)

Fig.3. The reflectance curve of: (a) GaAs and (b) GaInP.

The simulation curve give for GaAs $x_{j}=85 \mathrm{~nm}, x_{B}=1650 \mathrm{~nm}, x\left(T_{i} O_{2}\right)=190 \mathrm{~nm}$, $x\left(\mathrm{Al}_{2} \mathrm{O}_{3}\right)=900 \mathrm{~nm}$, and for GaInP $x_{j}=59 \mathrm{~nm}, x_{B}=188 \mathrm{~nm}, x\left(T_{i} O_{2}\right)=75 \mathrm{~nm}$, $x\left(\mathrm{Al}_{2} \mathrm{O}_{3}\right)=210 \mathrm{~nm}$.

Figure. 3 shows the perfect coherence between theoretical and simulation proposed, thus the absorption of GaAs is important in the range of wavelength $300-850 \mathrm{~nm}$, whereas for GaInP is in the range of $300-650 \mathrm{~nm}$. This result is very important to the next work, thus we can with the values of thickness $\mathbf{x}_{\mathbf{j}}$ and $\mathbf{x}_{\mathbf{B}}$ represent the curve of external quantum efficiency and density of current. Figures.4,5 show the total external quantum efficiencies QE and the integrated photocurrent density $I_{p h}$ of the two cells calculated from Eqs.(4)-(7). The external quantum efficiency is a function of wavelength, and the photocurrent density $J_{p h}$ is obtained from the integral of the product of quantum efficiencies (We can use too this rule ${ }^{[5]}: I_{p h}=$ $\left.\sum_{i=1}^{n}\left(J_{p h}\left(\lambda_{i}\right)\right)\right)$ 

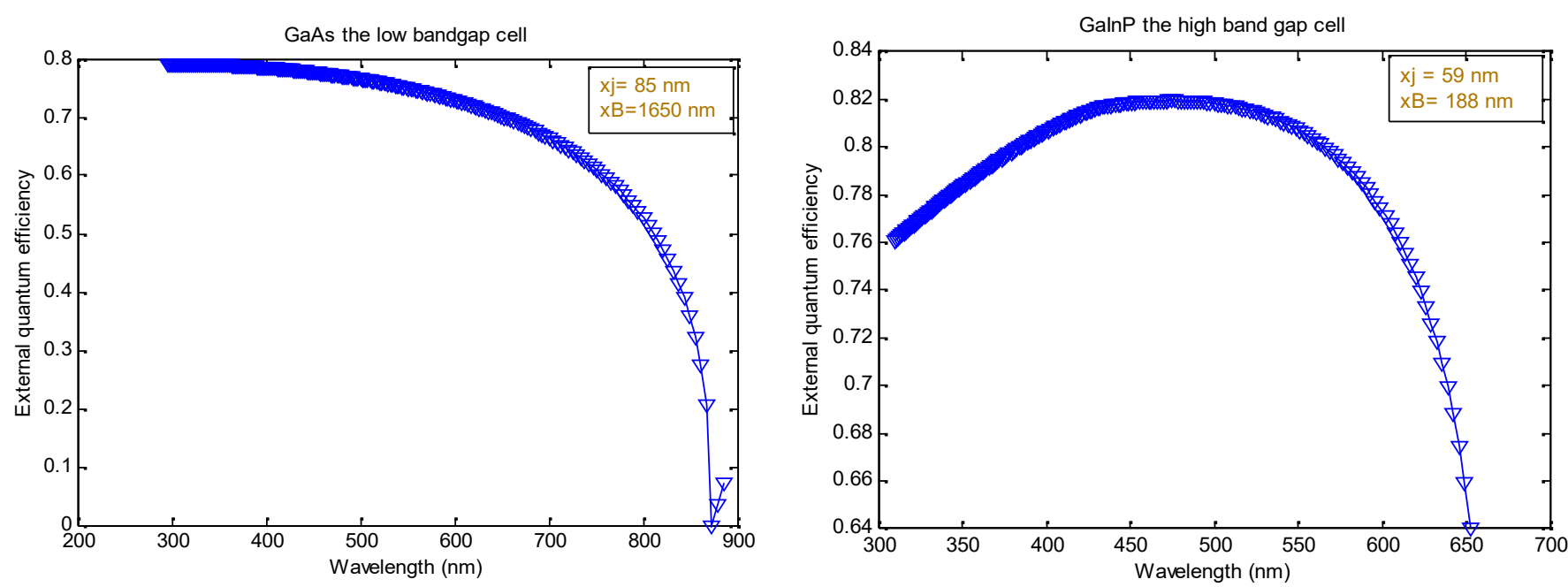

Fig.4. The external quantum efficiency of GaAs and GaInP
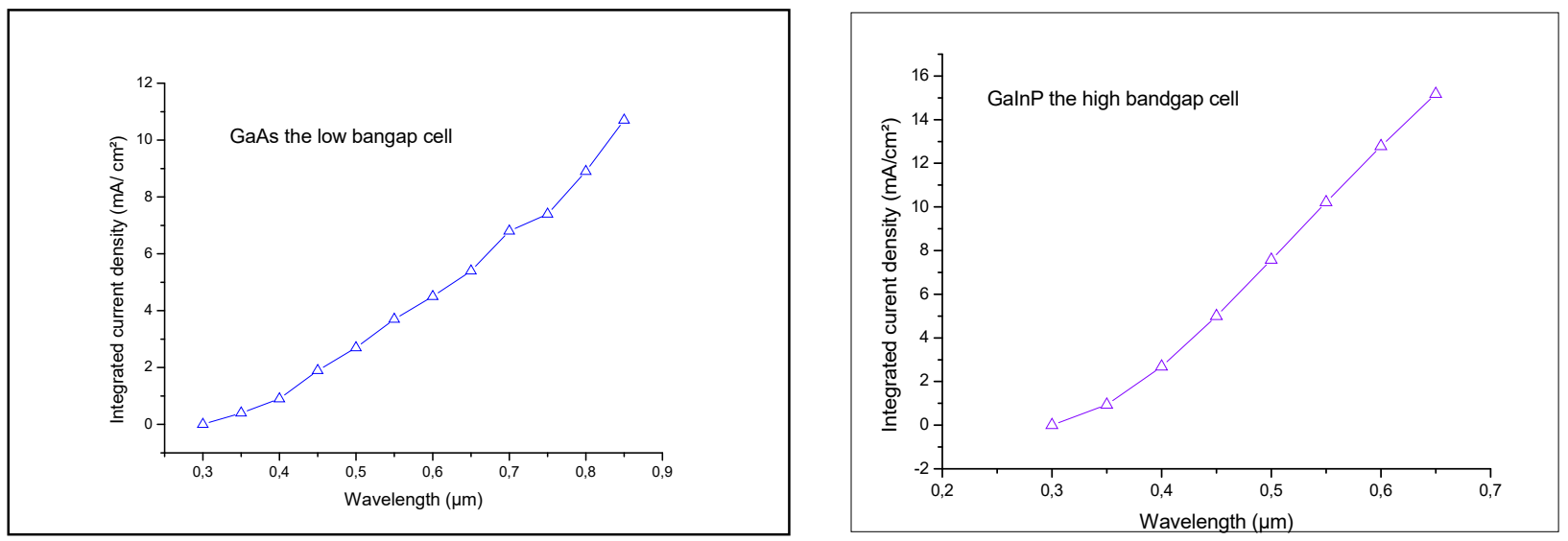

Fig.5. Integrated photocurrent density of GaAs and GaInP.

The high bandgap cell GaInP generates a photocurrent density of $16 \mathrm{~mA} / \mathrm{cm}^{2}$, the low bandgap cell generates only $10.7 \mathrm{~mA} / \mathrm{cm}^{2}$.

Figure.6 show I-V characteristics for each subcell GaAs and GaInP. For the case of a cell with the new structure without tunnel junction and with a serie connection between sub-cells, Jsc, Voc, FF and conversion efficiency $\eta$ were determined for each of the junctions. Fig.7 shows the $\mathrm{J}-\mathrm{V}$ curves for each of the sub-cells and the tandem cell in the new model. 

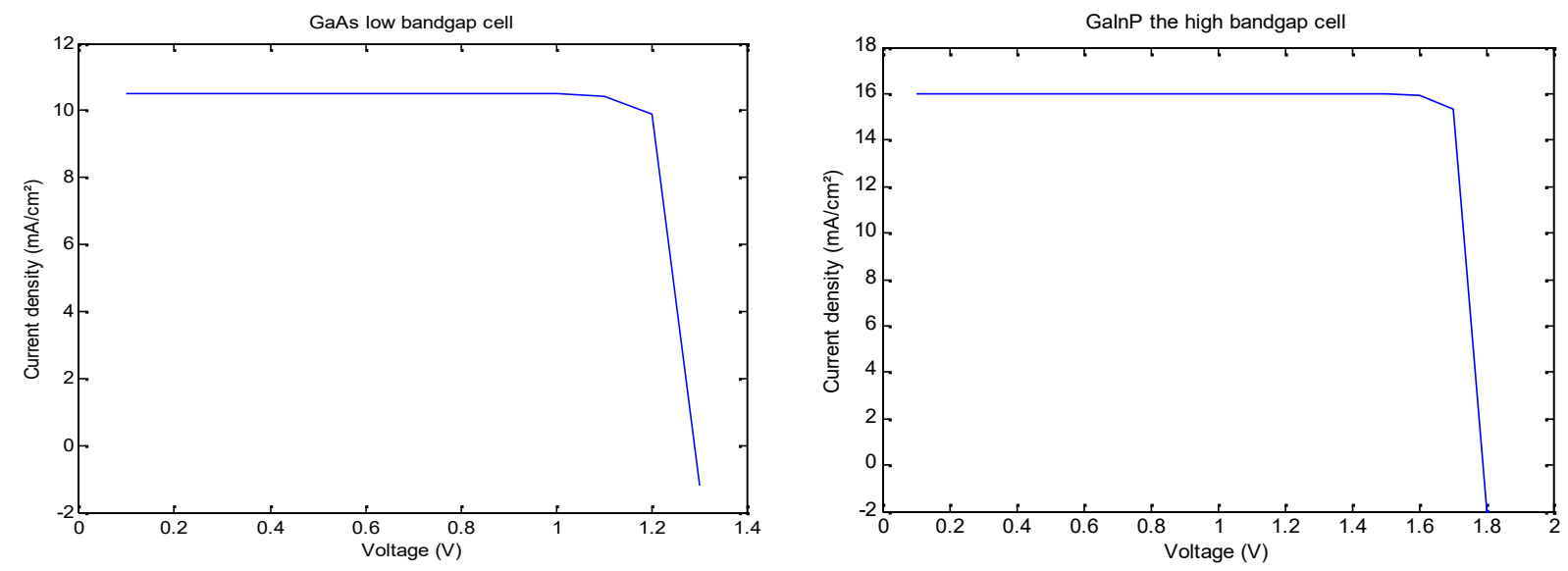

Fig.6. I-V characteristics of GaInP and GaAs under AM1.5.

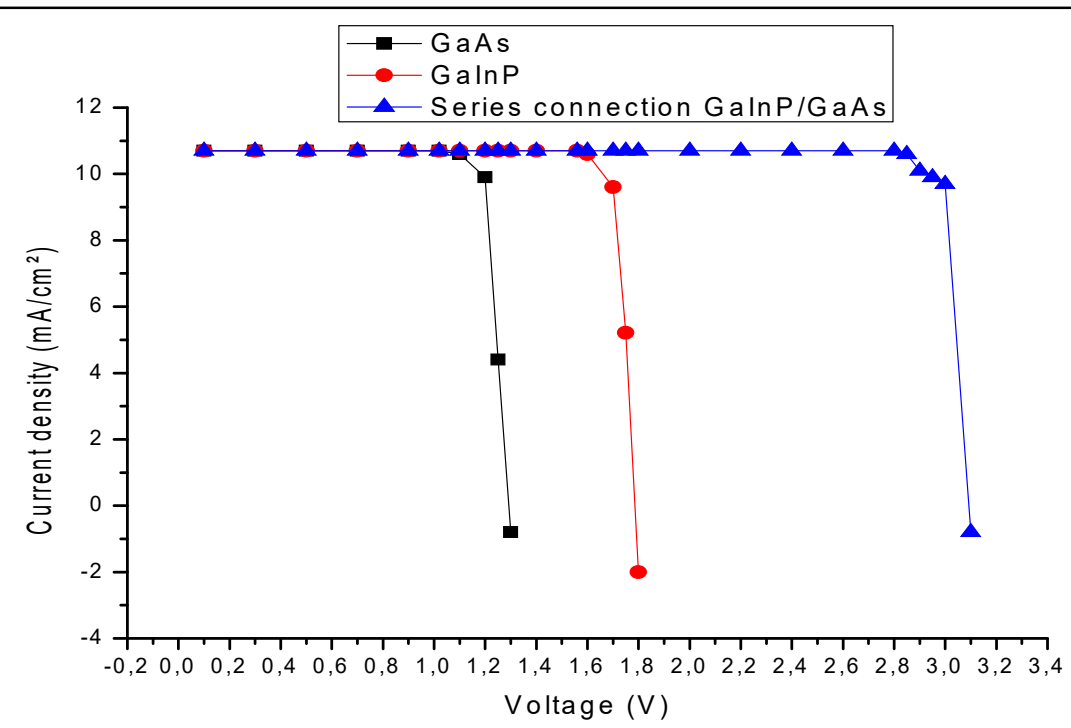

Fig.7. I-V characteristics of the series-connections between GaInP and GaAs under AM1.5

These curves for the series-connection cells was made using the equivalent circuit for 2 cells in series, $I_{p h}(\mathrm{GaInP})=J_{p h}(\mathrm{GaAs})=J_{p h}($ Series-connection model $)=10.7 \mathrm{~mA} / \mathrm{cm}^{2}$. The resultant $\mathrm{J}-\mathrm{V}$ and is shown in Fig.7. These results are summarized in Table.4. For the proposed tandem solarcell: $\mathrm{Jsc}=10.7 \mathrm{~mA} / \mathrm{cm}^{2}$, Voc $=3.1 \mathrm{~V}, \mathrm{FF}=0.88$ and $\eta=$ 43\%.Thisisexpected high conversionefficiencyundertheAM1.5solarspectrum, comparable to current technology two junctions olarcells, and therefore the GaInP/GaAs solarcell studied here is an attractive alternative for high efficiency solar energy conversion. 
Table4.Calculated current densities, open circuit voltage, fill factor, and power conversion efficiency for each of the sub-cells and for the full cell of new model model.

\begin{tabular}{ccccc}
\hline Solar cell & $\mathbf{J}_{\mathbf{s c}}\left(\mathbf{m A} / \mathbf{c m}^{2}\right)$ & Voc $_{\text {ov }}$ & FF & $\boldsymbol{\eta}(\%)$ \\
\hline GaAs & 10.7 & 1.3 & 86 & 17.5 \\
GaInP & 10.7 & 1.8 & 89.95 & 25.72 \\
$\begin{array}{c}\text { Series connection } \\
\text { model (GaInP with } \\
\text { GaAs) }\end{array}$ & 10.7 & 3.1 & 88 & 43.22 \\
\hline
\end{tabular}

\section{CONCLUSION}

In this study, we have investigated theoretically the energy conversion efficiency that might be archived by GaInP/GaAs mechanically stacked two-junction solar cell using optical model with parabolic trough concentrator. According to numerical simulation, we determined the optimized thickness of GaInP and GaAs. The optimal conversion efficiency was 43\%, which is higher than that of GaInP or GaAs single junction. Furthermore, the structure utilized in this work not only has high potential energy conversion efficiency, but also avoids the difficulties encountered in the technical difficulties of fabricating the tunnel junctionand the costs. The calculations would contribute to designing and fabricating high efficiency GaInP/GaAs mechanically stacked solar cell, and this new structure can be a new research direction in GaInP/GaAs two-junction solar cells.

\section{REFERENCES}

[1] M.A Green, K.Emery, Y.Hishikawa, W.Warta, E.D. Dunlop,Prog.Photovolt.21 (2013) 827.

[2] M.A Green, Prog. Photovolt 9 (2001) 123.

[3] R. Komiya, A. Fukui, N. Murofushi, N. Koide, R. Yamanaka, H. Katayama, in Proceedings of the international Photovoltaic Science and Engineering Conference, vol, 21, 2C-50-08.

[4] Handbook of photovoltaic science and engineering(Ed. A. Luque, S. Hegedus) (Chichester, England: JohnWiley \& Sons Ltd.: 2003).

[5] F. Dimroth, C. Baur, A.W. Bett, M. Meusel, G. Strob, $31^{\text {st }}$ IEEE Photovoltaic Specialists Conference (PVSC-2005),525 (Orlando, USA: 2005). 
[6] Masafumi Yamaguchi*, III-V compound multi-junction solar cells: present and future,Solar Energy Materials \& Solar Cells 75 (2003) 261-269.

[7] Fahrenbruch A L, Bube R H. Fundamentals of solar cells photovoltaic solar energy conversion. New York: Academic Press, 1983.

[8] Wurfel P. Physics of solar cells: from principles to new concepts.Wiley-VCH, 2005

[9] Refractive index and extinction coefficient of materials (book).

[10] Handbook of optical materials.

[11] Refractiveindex.info, refractive index database .

[12] M. Ghrib ${ }^{\mathrm{a}}$, M. Gaidi ${ }^{\mathrm{a}}$, T. Ghrib ${ }^{\mathrm{a}}$, N. Khedher ${ }^{\mathrm{a}}$, M. Ben Salam ${ }^{\mathrm{b}}$, H. Ezzaouia ${ }^{\mathrm{a}}$,

Morphological and optical properties changes in nanocrystalline $\mathrm{Si}$ (nc-Si) deposited on porous aluminum nanostructures by plasma enhanced chemical vapor deposition for Solar energy applications, Applied Surface Science 257 (2011) 9129-9134.

[13] Souici Fatma-Zohra, Modélisation d'une cellule solaire en couche mince à base de Cuivre Indium Sélénium(CuInSe2), faculte des sciences et sciences de l'ingenieur, Université Kasdi Merbah Ouargla

[14] Alain Ricaud, solar cells, The physics of the conversion photovoltaique to filiers materials and processes, page180. (book in French).

[15]Melissa J. Griggs*,Brendan M. Kayes, and HarryA. Atwater, p-n Junction Heterostructure Device Physics Model of a Four Junction Solar Cell, California Institute ofTechnology, Thomas J. Watson, Sr. Laboratoriesof Applied Physics, MC128-95,Pasadena, California 91125

[16] S. Petibon; «nouvelles architectures distribuées degestion et de conversion de l'énergie pour les applicationsphotovoltaïques » Université de Toulouse _ LAAS, Septembre2009.

\section{How to cite this article:}

Ganouni R, Talbi M, Ezzaouia H. The oretical modeling of a new structure of iii-v tandem solar cells by using parabolic trough concentrator. J. Fundam. Appl. Sci., 2017, 9(1S), 756767. 